\title{
Numerical analysis of side airbags deployment in out-of-position situations
}

\author{
D. Bendjaballah', A. Bouchoucha ${ }^{1}$, M. L. Sahli, ${ }^{1,2^{*}}$ and J-C. Gelin ${ }^{2}$
}

\begin{abstract}
Side-impact collisions represent the second greatest cause of fatality in motor vehicle accidents. Side-impact airbags have been installed in recent model year vehicle due to its effectiveness in reducing passengers' injuries and fatality rates. In meeting these requirements, simulations of folding and deploying airbags are very useful and are widely used. The paper presents a simulation method for the deploying airbags using three materials in different working conditions. Finite element analysis is primarily used to evaluate this concept. In these simulations, the gas flow is described by the conservation laws of mass, momentum, and energy. The numerical results indicate that the FE method in this paper is capable of capturing airbag deploying process accurately.
\end{abstract}

Keywords: Airbag simulations, Out-of-position, Crash, Modeling, Out-of-position

\section{Background}

The passive safety of cars has become a very high priority issue for the automotive industry. Today, there are not only one or two airbags in a car; certain models have ten times more than that. With the increasing usage of airbags, the number of accidents where the airbag itself can cause an injury to the occupant also increases (Augenstein et al. 2003; Gabauer and Gabler 2010; Audrey et al. 2011). As is well known, safety belts are also now devices designed to provide protection to the users of vehicles during crash events, minimizing the loads necessary to adapt their movement to the movement of the car (Freesmeier and Butler 1999; Schmitt et al. 1997). In general, the seat belt is designed to restrain the occupant in the vehicle and prevent the occupant from having harsh contacts with interior surfaces of the vehicles. The airbag acts to cushion any impact with vehicle structure and has positive internal pressure, which can exert distributed restraining forces over the head and face. As a safety component of automobile, an airbag decreases occupants' injury likelihood effectively in case of an accident (Ruff et al. 2007). These safety elements can reduce the death rates on the roads, and its protection effects have been widely approved

\footnotetext{
* Correspondence: Mohamed.sahli@femto-st.fr

${ }^{1}$ Mechanics Laboratory, Faculty of Technology Sciences, Mentouri Brother University, Constantine, Algeria

${ }^{2}$ Applied Mechanics Department, FEMTO-ST Institute, CNRS UMR 6174, Besançon, France
}

(Crandall et al. 2001; Teru and Ishikawa 2003). With computational tools such as finite element methods designed for dynamic contact problems, crashworthiness simulations can now be used with reliable accuracy to evaluate occupant protection in various collision conditions with safety metric/parameters such as acceleration, head injury criteria, intrusion distance, intrusion velocity, and neck forces (neck injury risk or whiplash). Thus, new types of airbag products are being developed to handle different collision scenarios.

In recent years, occupant protection airbags have become standard equipment on most new passenger vehicles (Braver and Kyrychenko 2004; Teng et al. 2007; Yoganandan et al. 2007). The airbag cushion is composed of a woven fabric which is rapidly inflated during a car crash. The airbag dissipates the passenger's kinetic energy thereby reducing injury through biaxial stretching of the fabric bag and escaping gas through vents. Therefore, the performance of the airbag is greatly influenced by the mechanical properties of the fabric. Generally, air bags are designed to deploy in a crash that is equivalent to a vehicle crashing into a solid wall at 8 to $14 \mathrm{mph}$. Air bags most often deploy when a vehicle collides with another vehicle or with a solid object like a tree. There are various types of airbags: frontal, side-impact, and usually larger than the driver airbags (see Fig. 1). 


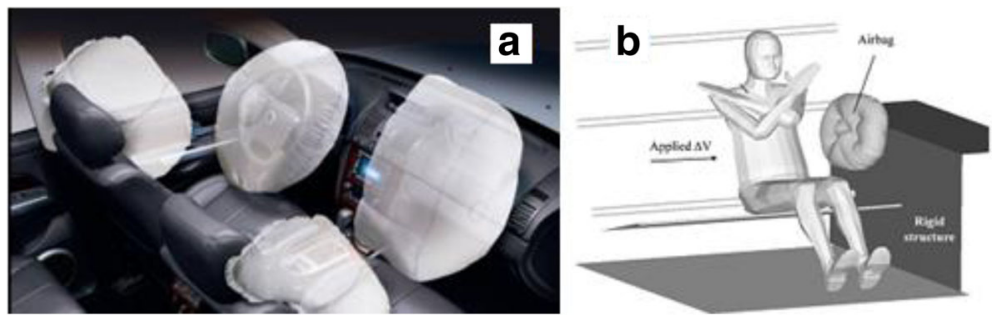

Fig. 1 a Frontal and side airbags. b Oblique view of facet occupant model in sitting posture following airbag deployment (Lim et al. 2014)

Extensive studies have shown that the airbag deployment in load cases consists of two occupant loading phases: a punch-out effect where the airbag bursts out of its container with the airbag and airbag module cover accelerating towards the occupant and a second loading phase during which the airbag is taking on its deployed shape and volume (membrane-loading effect). Bankdak et al. (2002) developed an experimental airbag test system to study airbag-occupant interactions during close proximity deployment. The results provided insight for simulating the effect of inflation energy and mass flow on target response. Bedard et al. (2002) found that while left-side (driver-side) impacts accounted for only $13.5 \%$ of all crashes, the fatality rate among these crashes was $68.3 \%$ in comparison to front impact (48.3\%), right-side impact (31.3\%), and rear impact (38.4\%). These studies underscore the importance of occupant safety during side-impact collisions. In the last years, the current market requested to reduce the time and cost airbag development. In order to achieve this result, virtual simulations play an important role since they allow to minimize the number of experimental tests (Pei et al. 2013; Cao et al. 2014). Several simulation models of airbag were established (Wang et al. 2007). It is feasible to optimize the parameters of airbag deployment using simulation technology. Experimental and numerical studies have quantified injury risks to closeproximity occupants from deploying side airbags. These studies have focused on the prevention of the most adverse effects of airbag deployment (Duma et al. 2003). Other studies have proposed airbag characteristics to minimize particular biomechanical responses (Haland and Pipkorn 1996). In a more recent study, Marklund and Nilsson (2003) compared deformation patterns with experimental data as well as the computational costs associated with three different airbag deployment simulation methods; they concluded that the SPH method is relatively inexpensive and produces incremental deformation patterns that compare most closely to the experimental results. The process of inflation of an airbag is one of the determining factors in saving lives. The duration from the initial impact of the crash to the full inflation of an airbag is about $40 \mathrm{~ms}$, and during this time, the airbag goes from being in a folded state to a fully inflated state, with a high internal pressure. After achieving this state, the airbag begins to deflate, thus providing a nice cushion for the body impacting it. Ideally, the person in the crash should come into contact with the airbag at this time. In the present study, a large volume passenger side airbag model is developed to handle different collision scenarios. The main aim is evaluate the performance of deploying of passenger side airbag using finite element methods (FEM).

\section{Methods}

Materials

The tensile specimens were made in different airbags ( $P$ : Peugeot, R: Renault, and VW: Volkswagen) with a length of $200 \mathrm{~mm}$ long and a width of $40 \mathrm{~mm}$. Table 1 shows the mechanical properties of the airbag.

\section{Tensile tests}

To determine the mechanical properties of the material of airbag used in the test pieces, tensile tests were performed on Lloyd EZ20 universal testing machine in the laboratory of Mechanical Testing of the University Constantine. These tests were conducted using rectangular samples. The axial force and axial displacement acquired during a test are converted into stress and the strain in order to be used for the fabric material model. The continuous recording of the stress-strain data was performed during both the load and unload phases. A minimum of five samples were made in order to check the repeatability of the measurements. All the data was collected by using a PC-based data acquisition system and analyzed by commercial software. The picture frame test device that is made for this study is shown in Fig. 2.

Table 1 Mechanical properties of the airbag

\begin{tabular}{ll}
\hline Parameters & Values \\
\hline Density $\left(\mathrm{kg} / \mathrm{mm}^{3}\right)$ & $9.100 \mathrm{E}-07$ \\
Young's modulus $(\mathrm{GPa})$ & 2.500 \\
Poisson's ratio & 0.345 \\
Thickness $(\mathrm{mm})$ & 0.150 \\
\hline
\end{tabular}




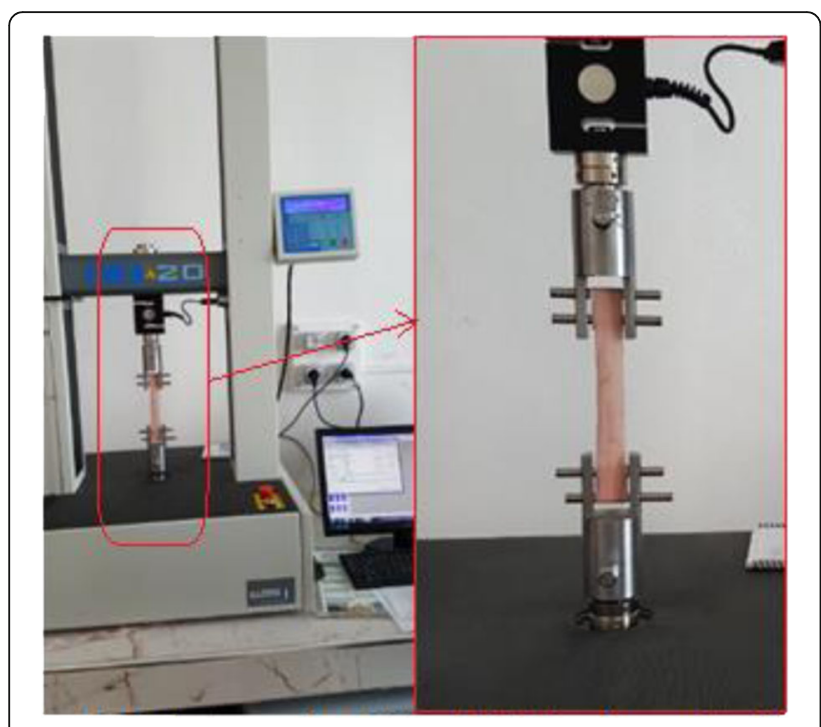

Fig. 2 A photograph of Lloyd EZ20 universal testing

Figure 3 shows the stress-strain relationship of the airbag sample under axial tensile loads. The results are showing a linear increase in extension with the increasing stresses. This is an expected output and it confirms with the theoretical behavior of a sample subjected to

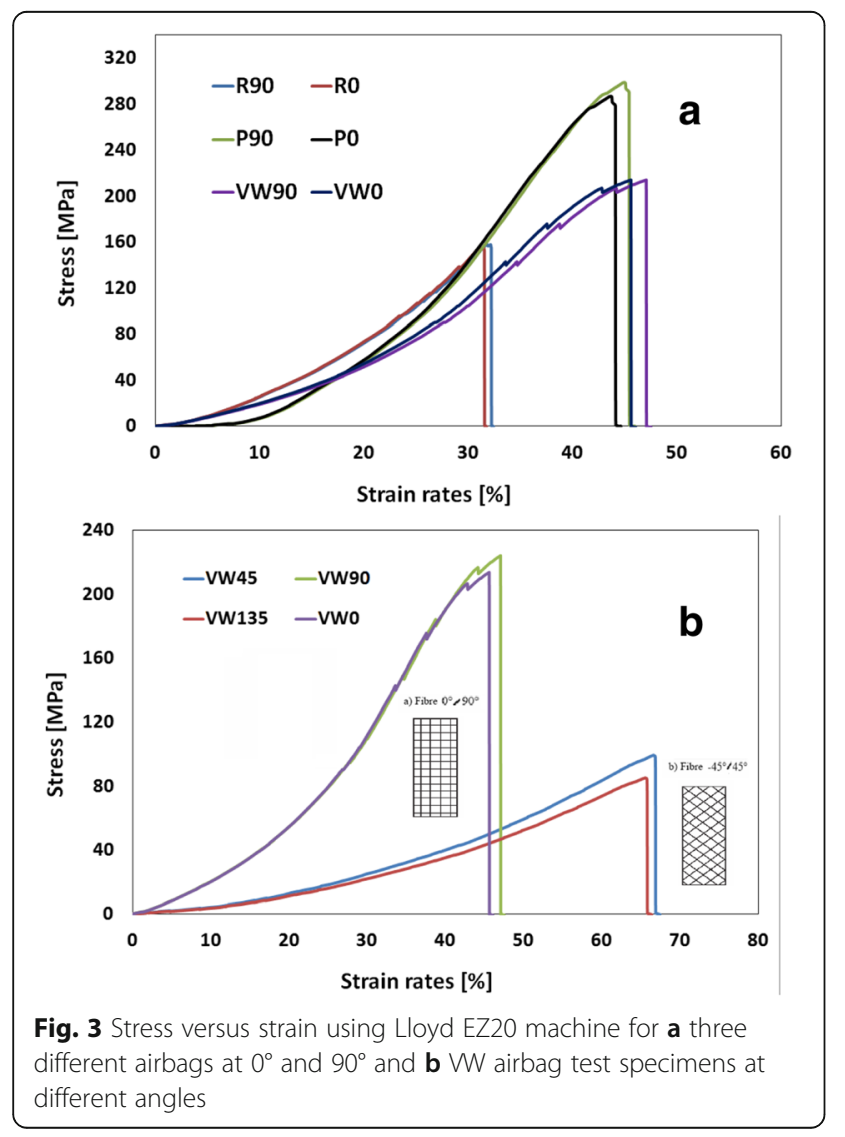

tensile stress. The rupture strain values for different airbags $(\mathrm{R} / \mathrm{P} / \mathrm{VW})$ were $0.322,0.441$, and 0.472 , respectively. The measured elastic parameters (i.e., Young's modulus E and initial yield strength) and Poisson's ratio are summarized in Table 2. The tensile tests of the woven fabrics can show differences on mechanical properties because woven fabrics can resist in-plane shear loads once the yarn lock-up angle has been reached. The differences of material property on material direction can affect the shape of fully deployed bag (see Fig. 3b).

\section{Finite element model of airbag simulation Theoretical background}

Numerical simulations of airbags use very complex and techniques such as an orthotropic model to identify the mechanical behaviors during the airbag inflation and the fluid mechanics (gas flow) to describe the inflator gas flow (pressure gradient) and improve the representation of the pressures within the airbag. To model the airbag as an orthotropic model, three material constants have to be provided. Assuming a plane stress condition, the material constitutive equations are given by [21]:

$$
\left\{\begin{array}{c}
\sigma_{1} \\
\sigma_{2} \\
\tau_{12}
\end{array}\right\}=\left(\begin{array}{ccc}
Q_{11} & Q_{21} & 0 \\
Q_{12} & Q_{22} & 0 \\
0 & 0 & Q_{66}
\end{array}\right) \cdot\left\{\begin{array}{c}
\varepsilon_{1} \\
\varepsilon_{2} \\
\gamma_{12}
\end{array}\right\}
$$

where $\sigma$ is the normal stress and $\tau$ is the shear stress, the subscript refers to the principal material directions, i.e., the fill and warp directions. Also, $\varepsilon$ and $\gamma$ are the strain components. The material elastic constants $Q_{\mathrm{ij}}$ are given by the following equations:

$$
\begin{aligned}
& Q_{11}=\frac{E_{1}}{1-v_{12} \cdot v_{21}}, Q_{12}=\frac{v_{12} \cdot E_{2}}{1-v_{12} \cdot v_{21}}=\frac{v_{21} \cdot E_{2}}{1-v_{12} \cdot v_{21}} \\
& Q_{22}=\frac{E_{2}}{1-v_{12} \cdot v_{21}}, Q_{66}=G_{12}
\end{aligned}
$$

where $E_{1}$ and $E_{2}$ are the Young's modulus in the fill and wrap directions and $G_{12}$ is the shear modulus of the fabric material. $v_{\mathrm{ij}}$ is the Poisson ratio of the material.

The gas exerts a pressure load on the airbag causing it to expand. This expansion puts the airbag under tensile stress lowering the expansion rate. In this study, heat

\begin{tabular}{|c|c|c|c|c|c|c|}
\hline \multirow[t]{3}{*}{ Properties } & \multicolumn{6}{|c|}{ Airbag } \\
\hline & \multicolumn{2}{|c|}{ Peugeot } & \multicolumn{2}{|c|}{ Renault } & \multicolumn{2}{|c|}{ Volkswagen } \\
\hline & $\overline{P 0}$ & P90 & $\overline{R O}$ & R90 & WO & WW90 \\
\hline Initial yield strength (MPa) & 285 & 292 & 155 & 154 & 210 & 213 \\
\hline Young's modulus (GPa) & 2.43 & 2.46 & 2.51 & 2.53 & 2.48 & 2.52 \\
\hline Poisson's ratio & 0.341 & 0.346 & 0.349 & 0.342 & 0.345 & 0.346 \\
\hline
\end{tabular}
conduction and heat transfer is not taken into account.

Table 2 Physical and mechanical properties of the airbag 
In the deployment of an airbag, an inflator supplies high velocity gas into an airbag causing it to expand rapidly. The gas inside the airbag is assumed to be ideal, to be of constant entropy, and to satisfy the equation of state:

$$
p=(\gamma-1) \cdot \rho \cdot e
$$

Here $p, \rho$, and $e$ are respectively the pressure, density, and specific internal energy, and $\gamma$ is the ratio of the heat capacities of the gas. The gas flow is described by the conservation laws for mass, momentum, and energy that read:

$$
\begin{aligned}
\frac{\mathrm{d}}{\mathrm{dt}} \int_{V} \rho d V+\int_{A} \rho(u \cdot n) d A=0 & \Rightarrow \quad \frac{\mathrm{d}}{\mathrm{dt}} \int_{V} \rho u_{i} d V+\int_{A} \rho u_{i}(u \cdot n) d A \\
& =-\int_{A} p n_{i} d A \\
\Rightarrow \frac{\mathrm{d}}{\mathrm{dt}} \int_{V} \rho e d V+\int_{A} \rho e(u \cdot n) d A & =-\int_{A} u_{i} p n_{i} d A
\end{aligned}
$$

here, $V$ is a volume, $A$ is the boundary of this volume, $n$ is the normal vector along the surface $A$, and $u$ denotes the velocity vector in the volume. Applying Bernoulli's equation in the case of an ideal gas with constant entropy gives:

$$
\frac{1}{2} u^{2}+\frac{\gamma}{\gamma-1} \frac{p}{\rho}=\frac{1}{2} u_{\mathrm{ex}}^{2}+\frac{\gamma}{\gamma-1} \frac{p_{\mathrm{ex}}}{\rho_{e x}}
$$

Here, the subscript ex denotes quantities at the throat of the tube. Furthermore $u, p$, and $\rho$ denote the quantities inside that part of the tube that is supplying mass. This gives

$$
u_{\mathrm{ex}}^{2}=\frac{2 \gamma}{\gamma-1}\left(\frac{p}{\rho}-\frac{p_{\mathrm{ex}}}{\rho_{e x}}\right)
$$

\section{Materials and boundary conditions}

The airbag system mainly consists of three parts: the airbag itself, the inflator unit, and the crash sensor or diagnostic unit. Thus, to study the behavior of the airbag using FE simulations, we need to have an FE model of the airbag in the folded position. A FE model of the airbag was used to simulate the test condition as shown in Fig. 5. LS-DYNA ${ }^{\circ}$ material model FABRIC (MAT_34) is used to simulate the airbag material. It is a variation of the layered orthotropic material model. Additionally, in the LS-DYNA ${ }^{\circ}$ material model, fabric leakage can be accounted for. However, for this $C A B$ material, the leakage is almost negligible and therefore no leakage is specified. The mechanical properties can be determined from the physical test. Typical material properties for airbag fabrics are taken as given in Chawla et al. (2004a) (Table 3). These properties are used to simulate inflation
Table 3 Material properties of airbag and rigid plate used in FE simulations (Chawla et al. 2004a)

\begin{tabular}{lll}
\hline Materials & Airbag & Rigid plate \\
\hline Density of fabric $\left[\mathrm{g} / \mathrm{cm}^{3}\right]$ & - & 7.84 \\
Young's modulus $[\mathrm{GPa}]$ & 2.5 & 206 \\
Poisson's ratio & 0.34 & 0.30 \\
Shear modulus [GPa] & 6.9 & - \\
\hline
\end{tabular}

Table 4 Initial values used for FE simulation of the swelling of passenger airbag (Deery et al. 1999)

\begin{tabular}{ll}
\hline Pressure $[\mathrm{Pa}]$ & $10^{4}$ \\
\hline Temperature $\left[{ }^{\circ} \mathrm{C}\right]$ & 25 \\
Universal gas constant $[\mathrm{kg} / \mathrm{kmol} . \mathrm{K}]$ & 8.314 \\
Initial pressure $[\mathrm{Pa}]$ & $1.01 \times 10^{4}$ \\
Molecular weight $[\mathrm{kg} / \mathrm{mol}]$ & 0.02802 \\
Added initial volume $\left[\mathrm{m}^{3}\right]$ & $3.33 \times 10^{-4}$ \\
\hline
\end{tabular}

process of airbag (see Table 1). The car dashboard is modeled as the rectangular thin plate using a MAT_RIGID material, and the degrees of freedom are constrained in all the directions. The similar properties of thermoplastic polymer are assigned for contact purposes. The porosity of the fabric is assumed zero. The nitrogen gas is taken for inflating the airbag. Properties of nitrogen gas and initial bag conditions are shown in Table 4. The example on which we perform the study is a typical passenger side airbag. The geometric details have been measured from a commercially available airbag. The initial state of the airbag is a closed rectangular whose sides are to be finished to $482 \times$ $635 \mathrm{~mm}^{2}$ and is shown in Fig. 4.

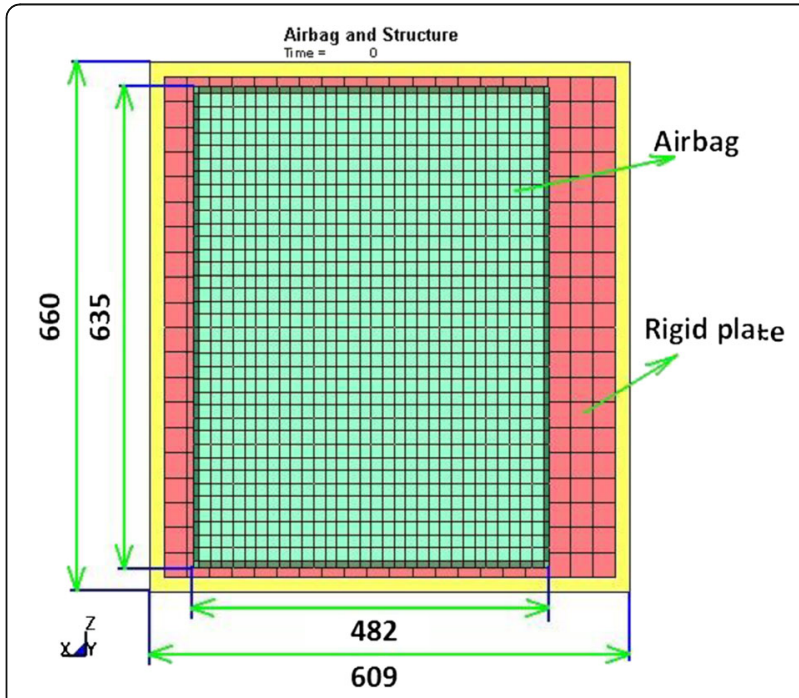

Fig. 4 The initial airbag geometry in the form of a rectangular 

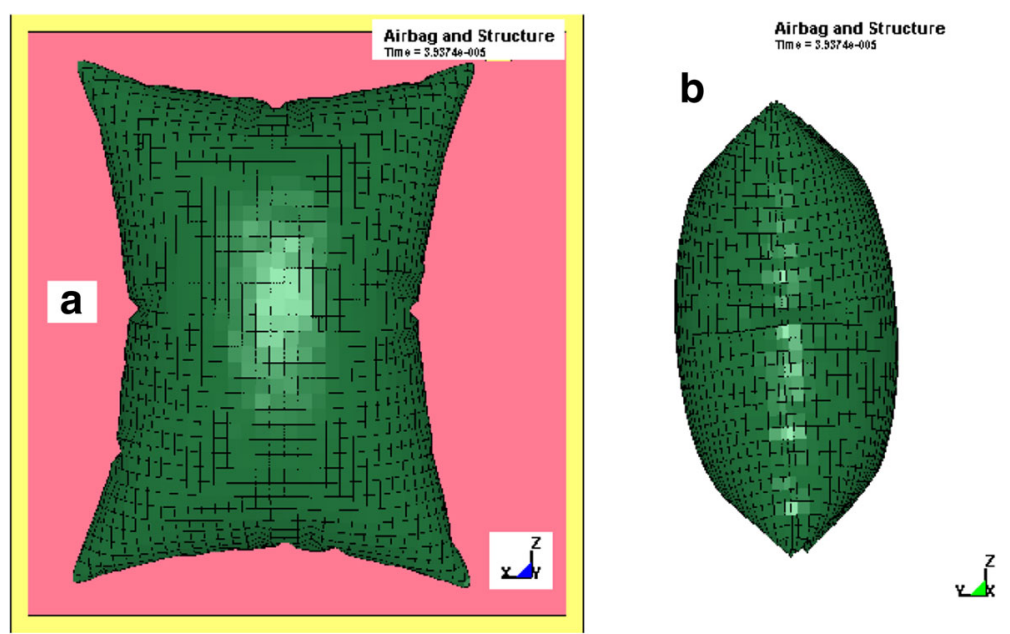

Fig. 5 Top view and isometric view of inflated airbag and rigid plate meshes

Airbag mesh is generated in Ansys ${ }^{\circledR}$ finite element software. It is consists of 2832 elements and 2875 nodes in the airbag mesh. Quadrilateral elements are used for airbag mesh. The airbag mesh is exported to Lsdyna ${ }^{\circ}$ software (see Fig. 5). All the simulations of the airbag deployment mesh are done in this software. Contact type 37 of Lsdyna $^{\circ}$ software is used for defining the contact between airbag mesh and rigid plates. This contact type is between node and surface. Airbag mesh is treated as nodes and rigid plates are taken as surface. In the simulation, the pressure generated by the gas is then uniformly applied to the internal surface of the airbag fabric. In the simulation, there will be an airbag surface and gas that fills up the inside of this surface. The airbag surface consists of flexible membrane elements that deform under tensile stresses and cannot carry compressive loads. The airbag control volume in LS-DYNA ${ }^{\circ}$ is the airbag control volume in LS-DYNA ${ }^{\circ}$ is modeled as an AIRBAG_SIMPLE_AIRBAG_MODEL to simulate the air test condition. A baseline model of the airbag is run using AIRBAG_LOAD_CURVE option. This gives an estimate of the volume of the airbag.

\section{Results and discussion}

Figure 6 shows the results for this deploying airbag halfway and at the end of the analysis. Due to the fact that

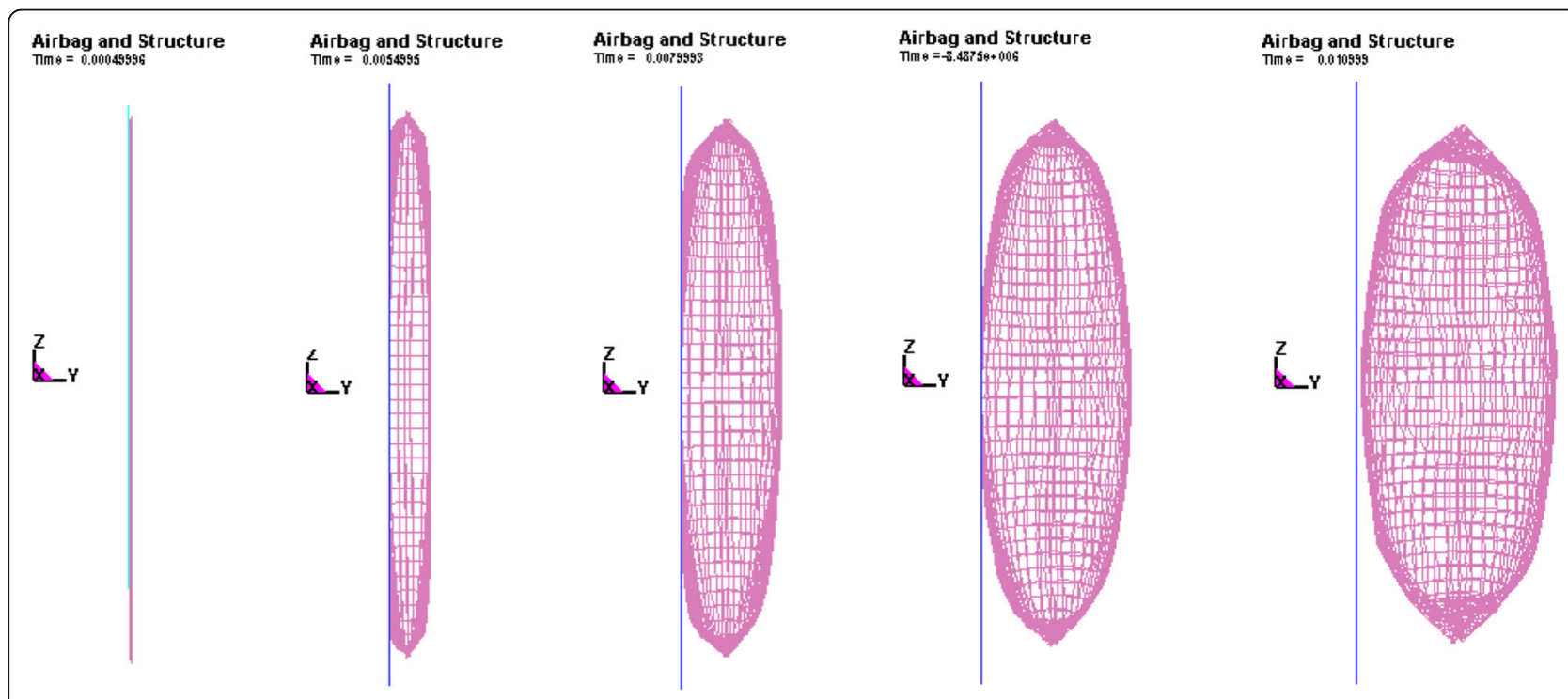

Fig. 6 Airbag deployment at $t=11 \mathrm{~ms}$ 


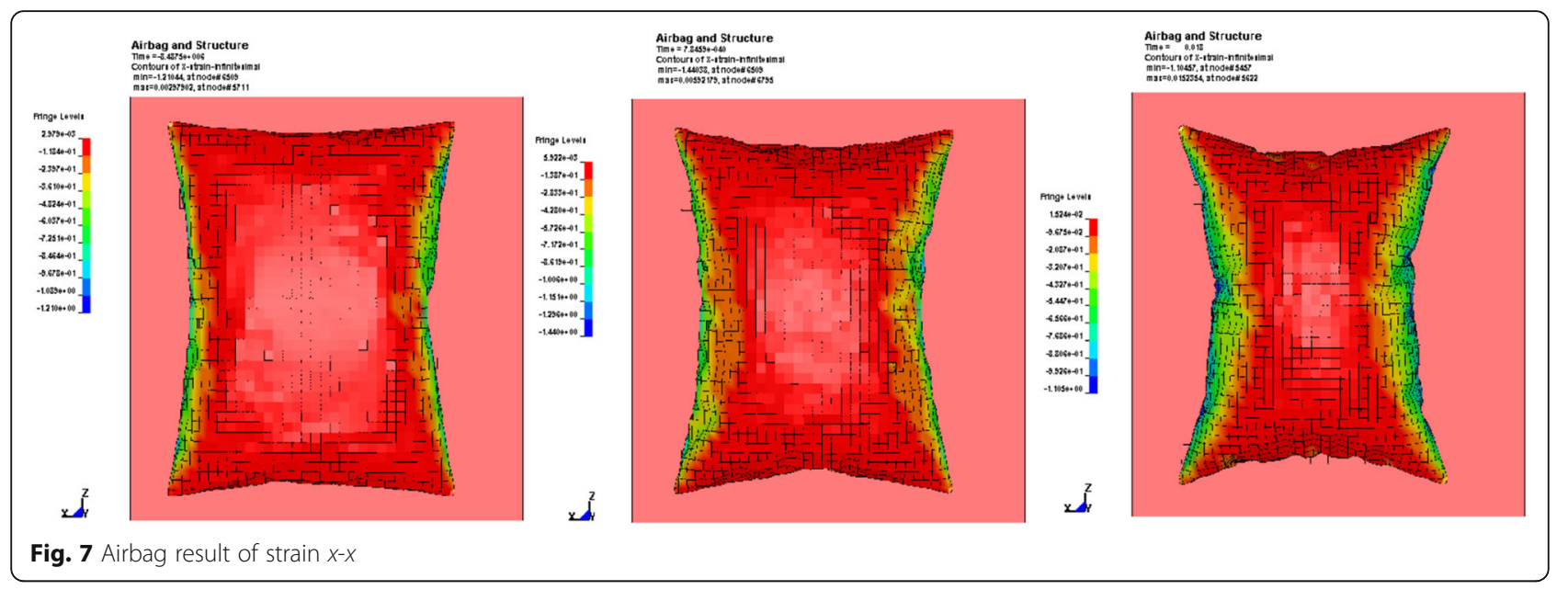

only $11 \mathrm{~ms}$ are simulated, the airbag is fully inflated as can be seen in Fig. 6. From the figures, it can be seen that the airbag module cover opens fully, as close to reality. The increasing of volume is coming mainly from the gas flow.

The final $x-x$ effective strain contours computed are plotted in Fig. 7. As shown in this figure, a state of deployment and swelling of passenger airbag with highly non-uniform deformation is detected around the bag. In the present analysis, the localized elastic strains reach values far below the rupture strain that can be measured in the tensile test (Wu et al. 2005). Nevertheless, according to the global material response, the constitutive model is found to be still valid at such high deformation levels. Moreover, the development of plaice can clearly be seen during the swelling of passenger airbag.
Figure 8 shows the displacement result during the airbag deployment versus time values. Initially, both surfaces of the airbag are close and parallel; then, as the maximum displacement estimated is the same one with low values recorded near the corners of the structure, they are concentrated little by little towards the center of the airbag. The final results of the swelling contours are characterized by a symmetric displacement. The airbag result displaces and the average pressure distribution inside the three different airbags are depicted in Fig. 9. They represent the end of swelling of passenger airbag, the final geometry of the bag, and the contour of pressure of the gas inside the bag. We can observe how not only the development of plaice of airbag but also the distribution of pressure is quite different from one case to another.

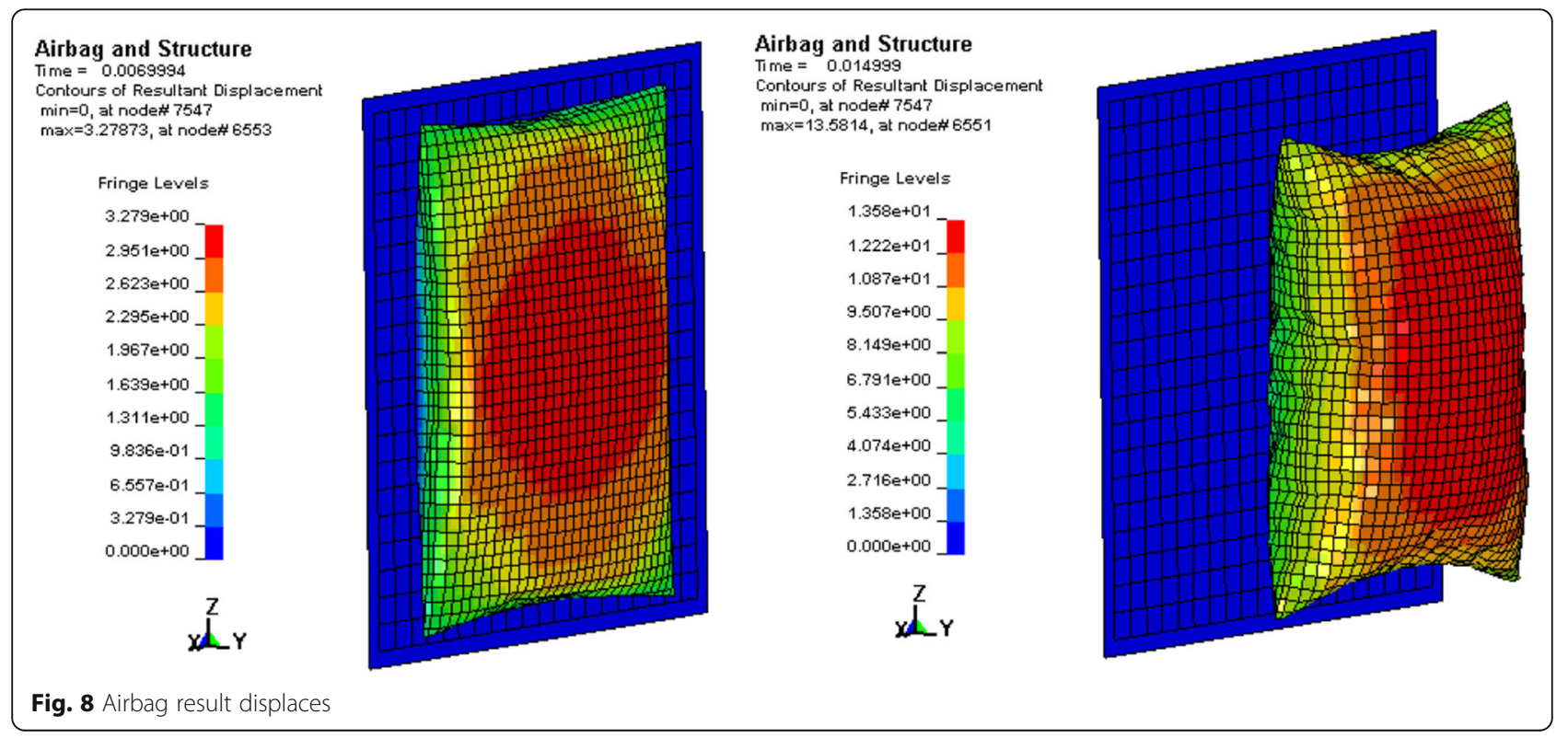




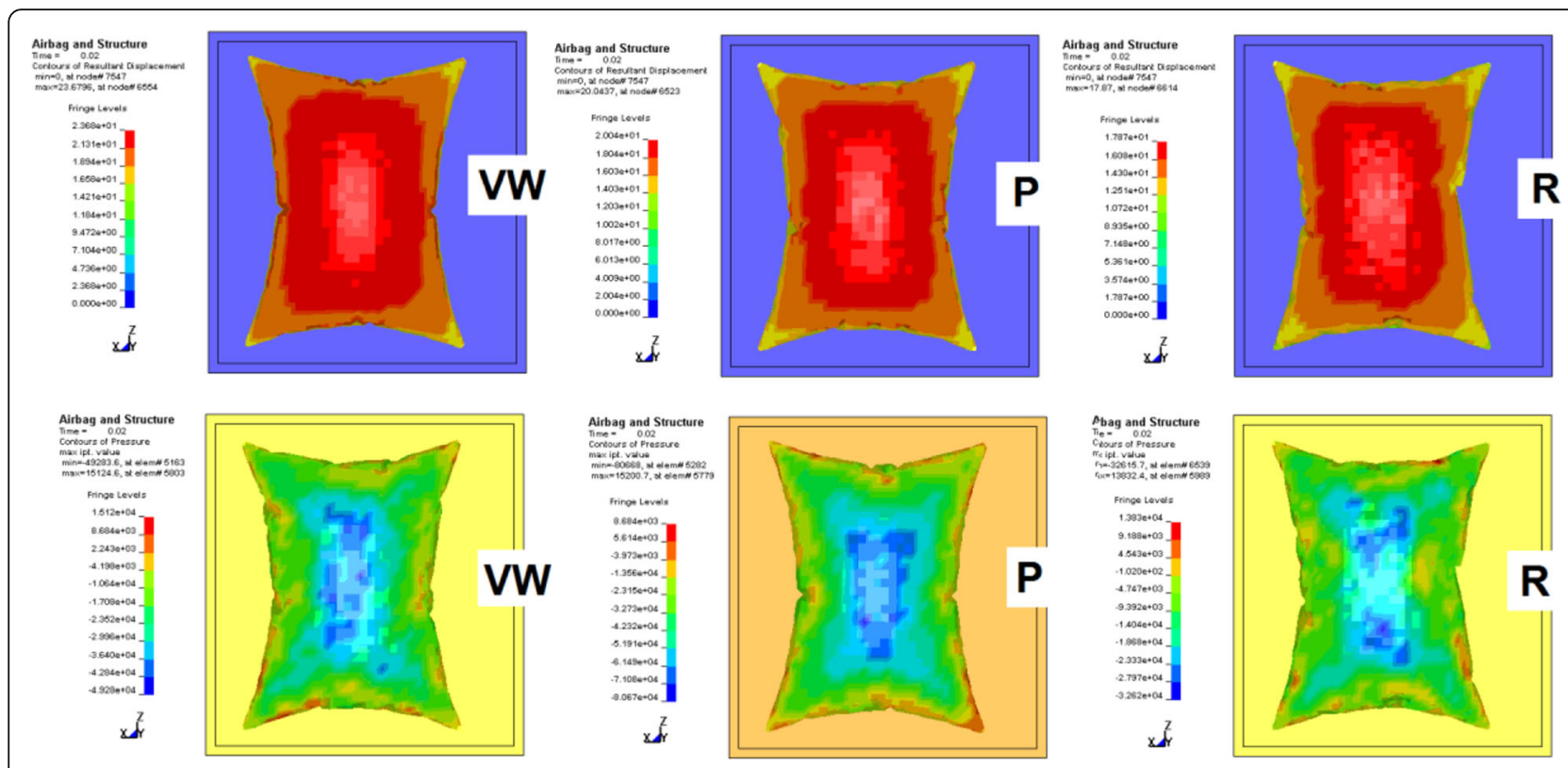

Fig. 9 Airbag result displaces and pressure using different airbags

In particular, we can see how configuration 3 deploys much less aggressively than, for instance, configuration 1. In this case, there is a quick evolution of the volume and the pressure at the same time (Blundell and Mahangare 2006).

The resulting pressure curves versus time of swelling airbag are plotted in Fig. 10 where the computed responses of different critical zones are apparent. As expected, during the swelling airbag phase, the maximum pressure values are saved at middle of the structure. Moreover, we have also seen after $30 \mathrm{~ms}$ the ratio between the maximum pressure differences is around $28 \%$. This difference is significantly dependent on the geometric form of the airbag (Blundell and Mahangare 2006; Chawla et al. 2004b). Figure 11 below shows the energy total of the system versus time history during the deploying of the airbag. The maximum value is observed at time $30 \mathrm{~ms}$. They increase significantly with the gas injection pressure in the bag. The total energy during the swelling airbag can be used to absorb the collision during crash, by the cushioning effect provided by the airbag, and by the deflation of the inflated airbag, which occurs due to the holes provided in the airbag fabric.

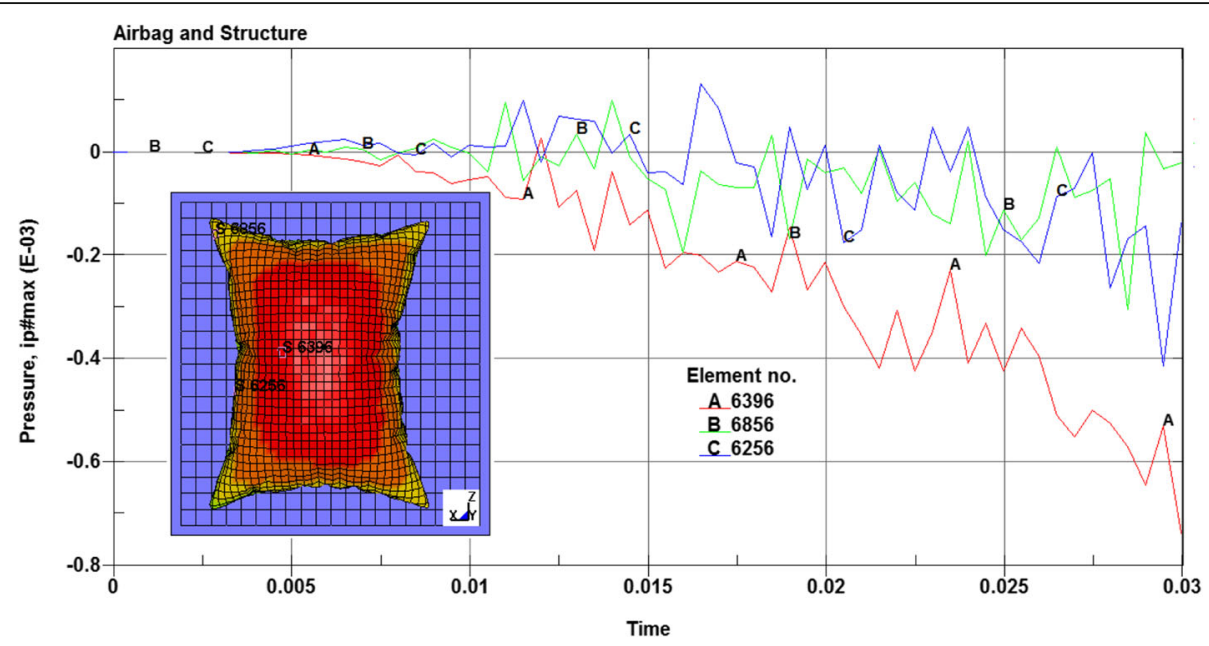

Fig. 10 Pressure evolution versus time 


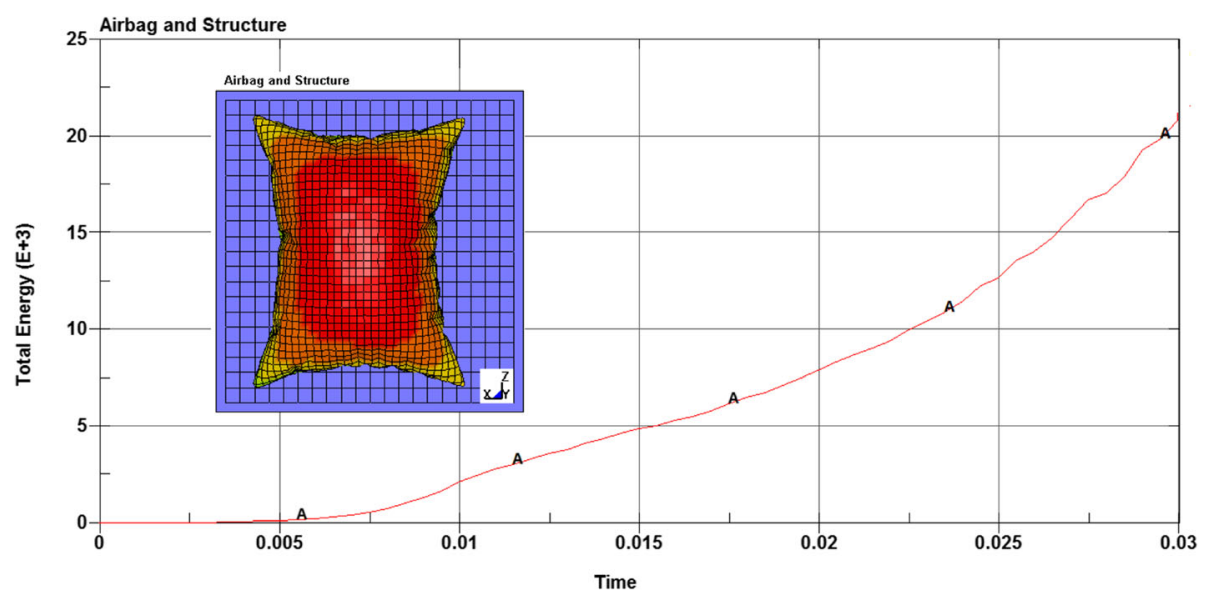

Fig. 11 Total energy versus time during the swelling airbag

\section{Conclusions}

This document outlines the current possibilities and limitations of the simulation of the first stages of the airbag deployment. The studies presented have been performed using a commercial airbag. The results first have allowed us to show that the airbag has been modeled correctly with a proper filling of the gas flow. As a result of this, simulation has proved to be a valuable tool to be taken into account in tasks related to airbag deployment.

In conclusion, these technologies are able to be used not only as a tool to solve problems related to the airbag development but also to help us arrive at a better understanding of the factors that influence the deployment of the airbag and its aggressiveness and therefore get more efficient and safer designs.

Further testing with real-life airbags and comparison with experiments is required. It is also very important to model proper folding for airbag mesh for studying contact interaction of out-of-position users with an inflating airbag. These will be carried out in the near future.

\section{Acknowledgements}

The authors would like to acknowledge the Applied Mechanics Department (DMA) at Franche-Comté University for support of this work.

\section{Authors' contributions}

All authors read and approved the final manuscript.

Received: 5 June 2016 Accepted: 28 December 2016

Published online: 18 March 2017

\section{References}

Audrey, H. D., Federic, R., Pacaux, M. P., \& Herve, M. (2011). Determination of preimpact occupant postures and analysis of consequences on injury outcome. Part: a driving simulator study. Accident Analysis and Prevention, 43, 66-74. Augenstein, J., Perdeck, E., Stratton, J., Digges, K., \& Bahouth, G. (2003). Characteristics of crashes that increase the risk of serious injuries. Annual proceedings / Association for the Advancement of Automotive Medicine. Association for the Advancement of Automotive Medicine, 47, 561-576.
Bankdak, F. A., Chan, P. C., \& Lu, Z. (2002). An experimental airbag test system for the study of airbag deployment loads. International Journal of Crashworthiness, 7, 129-161.

Bedard, M., Guyatt, G. H., Stones, M. J., \& Hirdes, J. P. (2002). The independent contribution of driver, crash and vehicle characteristics to driver fatalities. Accident Analysis and Prevention, 34, 717-727.

Blundell, M., \& Mahangare, M. (2006). Investigation of an advanced driver airbag out-of-position injury prediction with Madymo gas flow simulations. In Madymo User Meeting.

Braver, E. R., \& Kyrychenko, S. Y. (2004). Efficacy of side airbags in reducing driver deaths in driver-side collisions. American Journal of Epidemiology, 159, 556-564.

Cao, Y. H., Wu, Z. L., \& Huang, J. S. (2014). Numerical simulation of aerodynamic interactions among helicopter rotor, fuselage, engine and body of revolution. Science China Technological Sciences, 57, 1206-1218.

Chawla, A., Mukherjee, S., \& Sharma, A. (2004). Mesh generation for folded airbags. Computer Aided Design and Applications., 1, 269-276.

Chawla, A., Bhosale, P.V., Mukherjee, S. (2004a). Modeling of folding of passenger side airbag mesh. SAE International. 1-8

Crandall, C. S., Olson, L., \& Sklar, D. P. (2001). Mortality reduction with air bag and seat belt use in head-on passenger car collisions. American Journal of Epidemiology, 153, 219-224.

Deery, H., Morris, A. P., Fildes, B., \& Newstead, S. (1999). Airbag technology in Australian passenger cars: preliminary results from real world crash investigations. Journal of Crash Prevention and Injury Control, 1, 121-128.

Duma, S. M., Boggess, B. M., Crandall, J. R., Hurwitz, S. R., Seki, K., \& Aoki, T. (2003). Upper extremity interaction with a deploying side airbag: a characterization of elbow joint loading. Accident Analysis and Prevention, 35, 417-425.

Freesmeier, J. J., \& Butler, P. B. (1999). Analysis of a hybrid dual-combustion-chamber solid propellant gas generator. Journal of Propulsion and Power, 15, 552-561.

Gabauer, D. J., \& Gabler, H. C. (2010). The effects of airbags and seatbelts on occupant injury in longitudinal barrier crashes. Journal of Safety Research, 41, 9-15.

Haland, Y., \& Pipkorn, B. (1996). A parametric study of a side airbag system to meet deflection based criteria. Journal of Biomechanical Engineering, 118, 412-419.

Jones Robert, M. (1975). Mechanics of composite materials. Hemisphere Publ. Corporation

Lim, J-H., Park, J., Yun, Y-W., Jeong, S., Park, G. (2014). Design of an airbag system of a mid-sized automobile for pedestrian protection. Journal of Automobile Engineering, 21-33.

Marklund, P. O., \& Nilsson, L. (2003). Optimization of airbag inflation parameters for the minimization of out of position occupant injury. Computational Mechanics, 31, 496-504.

Pei, J., Yuan, S. Q., \& Yuan, J. P. (2013). Numerical analysis of periodic flow unsteadiness in a single-blade centrifugal pump. Science China Technological Sciences, 56, 212-221.

Ruff, C., Jost, T., \& Eichberger, A. (2007). Simulation of an airbag deployment in out-of-position situations. Vehicle System Dynamics, 45, 953-967. 
Schmitt, R. G., Butler, P., \& Freesmeier, J. (1997). Performance and CO production of a non-azide airbag propellant in a pre-pressurized gas generator. Combustion Science and Technology, 122, 305-350.

Teng, T. L., Chang, K. C., \& Wu, C. H. (2007). Development and validation of sideimpact crash and sled testing finite-element models. Vehicle System Dynamics, 45, 925-937.

Teru, I., \& Ishikawa, T. (2003). The effect of occupant protection by controlling airbag and seatbelt. Proceedings of the $18^{\text {th }}$ International Technical Conference on the Enhanced Safety of Vehicles. Nagoya: NHTSA.

Wang, Y. E., Yang, C. X., \& Peng, K. (2007). Airbag cushion process simulation for cargo airdrop system. Journal of System Simulation, 19, 3176-3179.

Wu, W. T., Hsieh, W., Huang, C. H., \& Wang, C. H. (2005). Theoretical simulation of combustion and inflation processed of two-stage airbag inflators. Combustion Science and Technology, 117, 383-412.

Yoganandan, N., Pintar, F., Zhang, J., \& Gennarelli, T. A. (2007). Lateral impact injuries with side airbag deployments - a descriptive study. Accident Analysis and Prevention, 39, 22-27.

\section{Submit your manuscript to a SpringerOpen ${ }^{\circ}$ journal and benefit from:}

- Convenient online submission

- Rigorous peer review

- Immediate publication on acceptance

- Open access: articles freely available online

- High visibility within the field

- Retaining the copyright to your article

Submit your next manuscript at $\gg$ springeropen.com 